\title{
An investigation of design waste causes in construction
}

\author{
M. Osmani, J. Glass \& A. D. F. Price \\ Department of Civil and Building Engineering, \\ Loughborough University, UK
}

\begin{abstract}
The construction, demolition and excavation waste arising in the UK is estimated at 109 million tonnes per year. Much had been published on ways to improve on-site waste management and recycling activities but very few attempts made to address design generated waste. This paper examines previous studies on architects' approach towards construction waste minimisation; and by means of a postal questionnaire sent to the 100 top UK architectural practices, investigates: the origins of design waste; waste minimisation design practices in the UK; and barriers to design out waste. The findings reveal that architects consider that waste is mainly produced during site operations and rarely generated during the design stages. However, about one third of construction waste could essentially arise from design decisions. Results also indicate that a number of constraints, namely: lack of interest from clients and attitudes towards waste minimisation are seen as disincentives to a proactive and sustainable implementation of waste reduction strategies during the design process.
\end{abstract}

Keywords: UK, design waste, construction, architects, waste minimisation.

\section{Introduction}

The construction sector in the UK generates around 109 million tonnes of waste each year [1]. As the rate of construction in the UK is set to increase, there is a pressing need to reduce waste at all stages of construction by considering the long-term impacts of design, build and waste management. There is a consensus in literature that a substantial amount of construction waste originates as a result of poor design [2-5]. The architect therefore has a decisive role to play in helping to reduce waste in construction at all levels by focussing on designing 
out waste [6-8]. By improving waste minimisation design practices architects could realistically and successfully accelerate the pace of change. The aim of this study is to assess architects' views on the origins of design waste, current waste minimisation design practices in the United Kingdom (UK), and barriers to construction waste minimisation.

\section{Addressing construction waste}

Research reports, such as the work of [8], aim to promote awareness in the building construction industry about the benefits of waste minimisation, including cost savings, and environmental issues and use of recycled and reclaimed materials. The "three Rs" principle of waste (reduction, re-use and recycle), otherwise known as the waste hierarchy, has been widely adopted. Similarly, the impact of legislation, particularly the Landfill Tax, and its effects on the behaviour and practices of the construction industry has resulted in a number of research studies. Additionally, tools, models and techniques have been developed to help handle and better manage on-site waste generation. While these tools facilitate auditing, assessment and benchmarking; waste source evaluation approaches do not offer long-term benefits, because they fail to address fundamental causes of waste. Furthermore, the last few years many waste minimisation and recycling guides have been produced (e.g. [7]). These documents give broad guidance for architects to adopt a waste minimisation approach in their projects; however, the recommendations in these guides do not realistically relate waste to all parameters of the architects' environment, including the complex design and construction process and the supply chain. Additionally, they do not specifically identify waste-stream components in relation to their occurrence during the architectural design stages. Consequently, literature in the field deals with waste that has already been produced, but there is insufficient effort and no structured approach to address waste at source, i.e. "design waste". For the scope of this study, 'waste minimisation' is defined as "the reduction of waste at source, by understanding and changing processes to reduce and prevent waste" [9]. Similarly, 'design waste' is defined as 'the waste arising from construction sites owing directly or indirectly to the design process" [6].

\section{Design waste minimisation approaches}

The extant literature reveals various approaches, guidelines and strategies to reduce design waste. These broadly cover four major axes of the design process including contract language: design issues and construction techniques; building materials specification; and education.

First, contract and contractual agreement stages could play a decisive role in reducing waste through incorporating waste minimisation activities by means of the use of specifically-oriented contract tender clauses. For example Dainty and Brooke [10] suggested using contractual clauses to penalise poor waste performance. Greenwood [7] went further to call for a fully integrated waste minimisation system at the contractual stage that "should identify and 
communicate the responsibilities for waste minimisation between all project stakeholders".

Secondly, literature reveals that substantial amount of waste is directly related to late changes during site operations. Hylands [11] identified standardisation of design as a construction method to improve buildability and reduce the quantity of off-cuts. Gibb [12] argued that standardisation and prefabrication of both building layouts and components result in less waste. Similarly, Baldwin et al. [13] argued that pre-casting and prefabrication offer significant opportunities to reduce waste.

Thirdly, waste can be reduced in a number of ways by specifying the use of efficient framing techniques, standard size supplies, and prefabricated components into the design. However, designers are often reluctant to specify recycled materials in their projects, mainly due to: concerns related to their properties; guaranteed standards uncertainties; and lack of knowledge.

Finally, education programmes could potentially help the client and other stakeholders appreciate waste minimisation benefits and the strategies to be employed in the project to achieve set targets. This will "ensure that the client understands the need for process and attitudinal change and that would encourage them to influence waste conscious design and construction practices from the inception of projects" [10, p.24]. However, the flow of information and dissemination of best practice to reduce design waste requires commitment and effective consultation and communication involving all project stakeholders.

The above guidelines could ensure that architects take the lead in educating their clients to recognise waste minimisation benefits and adopt waste reduction strategies in their projects. However, these are broad design guidelines without a comprehensible and focussed methodology to implement and sustain them. What architects need, which literature did not identify, is a clear and comprehensive tool to assist them in incorporating waste minimisation strategies during all stages of the design process. This paper is part of a research project that aims to develop a method of facilitating and sustaining the integration of waste minimisation within building design.

\section{Methodology}

A questionnaire was disseminated to the UK 100 top architectural practices, selected from The Architects' Journal [14]. The Architects' Journal ranking of architectural practices is based on the number of qualified architects within the firms. Partners and associates were targeted within the sampling frame, as they lead the decision-making process over the wider context of planning, design and implementation matters within their architectural practices. The survey was designed with six sections and a total of 22 questions; and included a combination of rating scales, multiple-choice questions and open-ended questions. Responses were requested based on current or recently completed building design projects. The quantitative responses were analysed using the Statistical Package for Social Science (SPSS). 


\section{Data results and analysis}

Of the 100 architectural practices surveyed, 40 questionnaires were received, representing a response rate of 40 per cent. The respondents' responses to the main theme of the research are examined below.

\subsection{Causes of design waste}

The questionnaire gave each respondent an opportunity to rate six variables that contributed to construction waste during design stages on a scale from one (not a waste cause) to five (major waste cause); the findings are shown in Figure 1.

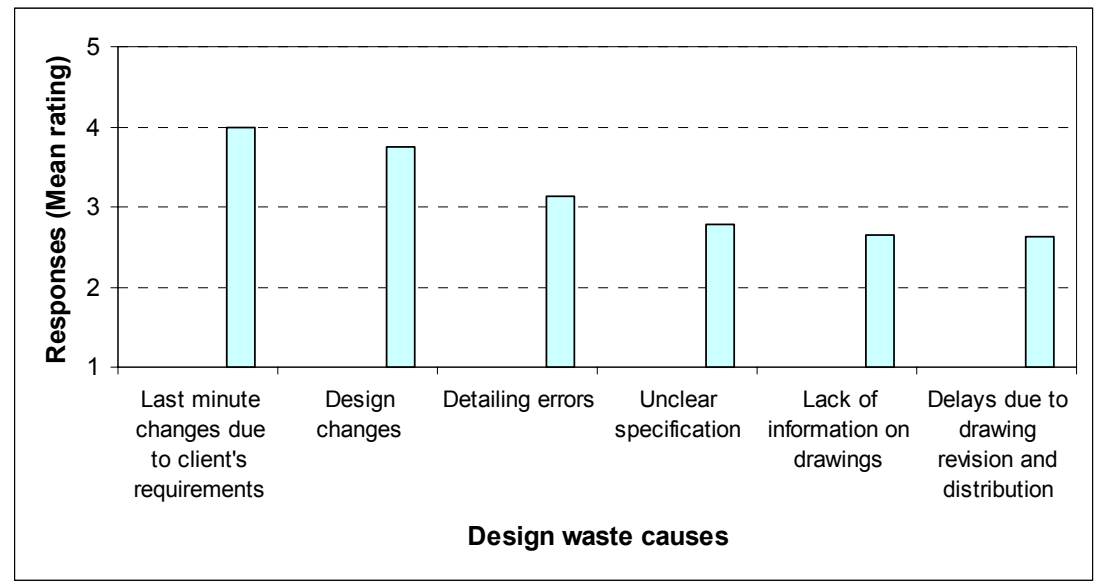

Figure 1: Causes of construction waste during design stages (respondents' views).

Figure 1 reveals that "last minute changes by client" was accorded the highest attribute of waste during design stages. Additionally, architects graded "design changes" as the second highest mean importance rating. However, only very few responding architects were of the opinion that "lack of information on drawings" was a major cause of design waste; while less than a fifth reported that "delays due to drawing revision and distribution" often led to waste generation. Respondents were asked to list other causes of waste during the design stages. There was a shared view that "not designing to minimise waste in mind" and "not designing for standardisation and to unit sizes" are major contributors to waste during the early stages of design. Furthermore, they identified other influencing factors namely: no consultation process; incorrect and over specification; and time pressure.

\subsection{Waste minimisation design strategies}

Informants were asked to rate from 1 (never been used) to 5 (used in all projects) the extent of integration of design waste strategies within their projects. Figure 2 
shows that very few attempts were made to design in waste reduction strategies. Additionally, the results revealed that none of the responding architects conducted "feasibility study of waste estimation" as a matter of course in all their projects as a common practice. However, more than a third of the surveyed architects claimed that they used, whenever possible, standard dimensions and prefabricated units to avoid on-site materials cutting.

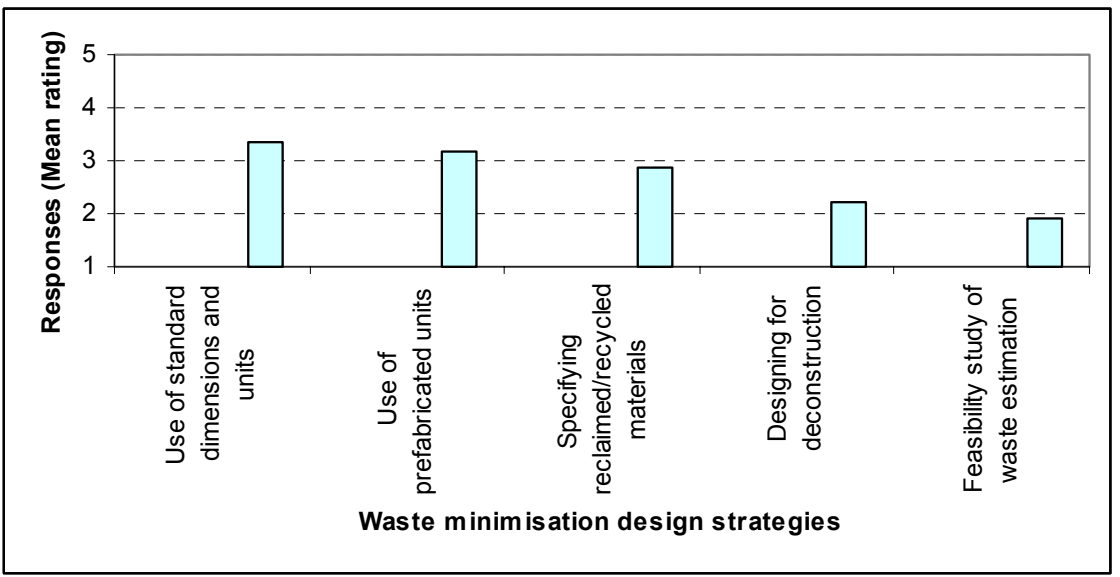

Figure 2: Extent of implementation rating of waste minimisation strategies (respondents' views).

\subsection{Design waste minimisation barriers and incentives}

Results of barriers and incentives to waste minimisation practices are summarised in Table 1. Although there is a broad equal rating of constraints,

Table 1: Waste minimisation barriers and incentives (respondents' views).

\begin{tabular}{|l|c|c|}
\hline \multirow{2}{*}{\multicolumn{1}{|c|}{ Barriers }} & \multicolumn{2}{c|}{ Responses } \\
\cline { 2 - 3 } & Mean rating & Ranking \\
\hline Lack of interest from clients & 3.88 & $\mathbf{1}$ \\
\hline Waste accepted as inevitable & 3.83 & $\mathbf{2}$ \\
\hline Poorly defined individual responsibilities & 3.80 & $\mathbf{3}$ \\
\hline Lack of training & 3.70 & $\mathbf{4}$ \\
\hline \multicolumn{1}{|c|}{ Incentives } & Mean rating & Ranking \\
\hline Legislation & 4.55 & $\mathbf{1}$ \\
\hline Financial rewards & 4.55 & $\mathbf{1}$ \\
\hline Waste management policy in place & 3.93 & $\mathbf{2}$ \\
\hline Training & 3.90 & $\mathbf{3}$ \\
\hline
\end{tabular}


responding architects ranked "lack of interest from clients" as the major barrier that impede design waste reduction. Additionally, "waste accepted as inevitable" and "poor defined individual responsibilities" were also reported as the next most significant hindrances to waste reduction; followed closely by "lack of training".

Conversely, informants established a clear hierarchy of incentives, as shown in Table 1, by equally ranking "legislation" and "financial rewards" as the two key incentives that could drive waste reduction during the design process. They also acknowledged that "waste management policy in place" and "training" are important factors in assisting architects to design out waste.

\section{Discussion}

The findings of the survey clearly indicate that waste minimisation is not a priority during the design process, reinforcing research. Additionally, changing current attitudes towards waste minimisation and understanding the underlying origins and causes of design waste were identified as significant hurdles that architects would need to overcome and comprehend prior to adopt and sustain waste reduction design activities in their projects. It is interesting to note that client activities could be a major origin of design waste through variation orders. Indeed design changes to meet client's changing requirements and preferences were ranked top of design waste causes. This was echoed by the findings of Ekanayake and Ofori [3]. Additionally, detailing errors were identified as significant origins of waste during the design process. Similar results were provided by Faniran and Caban [4].

Notwithstanding current architects' practices failed to make considerable inroads to curb waste production through design, many respondents concurred that waste reduction must be addressed at source and be a consideration at the concept stages, however, most of them acknowledged that designing out waste is not being implemented at present, as one respondent put it: "waste reduction is rarely considered during daily life in an architect's office". However, respondents reported that lack of interest from clients and 'waste accepted as inevitable' were their major concerns. On the other hand, there was consensus among informants that financial rewards and legislation are by far the key incentives to drive waste minimisation.

Training was seen by the survey's participants as a catalyst for a change in the design culture and practices. However, architects argued that widely and easily accessible sources of information are necessary. One respondent commented: "I have seen very little information on training offered in this field. We would probably make use of it far more if readily available, accessible and inexpensive courses were on offer to architectural practices".

The results of this survey indicate that architects' lack of engagement with designing out waste may be due to two reasons: a lack of understanding of what create design waste; and the assumption that waste minimisation is the contractor's responsibility. 


\section{Conclusions}

The aim of this paper was to review construction waste through design; evaluate design waste minimisation practices within the largest UK architectural practices; and assess barriers that impede architects to design out waste. The findings revealed that most responding architects seemed reluctant to adopt waste design minimisation strategies on their projects. Although respondents agreed that waste is a significant concern in construction, they shared the view that waste minimisation is often a low priority in the strategic planning and design activities of projects. Informants claimed that waste is predominantly produced during on-site activities and rarely generated during design stages. Nonetheless, architects conveyed their willingness to work with consultants and contractors to design out waste if incentivised by clients, particularly if they gained an enhanced fee for waste minimisation feasibility and implementation studies. It is interesting to note that minimising waste is considered as an ad hoc activity not part of the core activities of building design process. On the other hand, architects believed that there are a number of obstacles to designing out waste; namely perception of waste, unknown root causes of design waste, clients' requirements, and poorly defined responsibilities. Legislation and financial rewards were seen as the major incentives that could have a major impact on design waste reduction practices. This would suggest that increased fiscal measures and the introduction of systems of waste minimisation performance rewards rather than fines would have more effects on waste minimisation practices than voluntary approaches. Additionally, by acknowledging the need to understand the underlying causes of waste, architects recognised that training is a pressing issue.

\section{Acknowledgement}

The authors are very grateful to all architectural practices for their helpful collaboration in completing the questionnaire.

\section{References}

[1] DEFRA (Department for Environment, Food and Rural Affairs). Consultation on Site Waste Management Plans for the Construction Industry, DEFRA: London, 2007 pp. 65.

[2] Innes, S. Developing Tools for Designing Out Waste Pre-site and On-site, Proceedings of Minimising Construction Waste Conference: Developing Resource Efficiency and Waste Minimisation in Design and Construction, October 21 2004, New Civil Engineer, London, United Kingdom.

[3] Ekanayake, L.L., Ofori, G. Construction Material Waste Source Evaluation, Proceedings of the 2nd Southern African Conference on Sustainable Development in the Built Environment: Strategies for a Sustainable Built Environment, Pretoria, 23-25 August 2000. 
[4] Faniran, O.O., Caban, G., 1998. Minimizing Waste on Construction Project Sites. Engineering Construction and Architectural Management 5(2), pp. 182-88.

[5] Bossink, B.A.G., Brouwers, H.J.H. Construction Waste: Quantification and Source Evaluation. Journal of Construction Engineering and Management ASCE 122(1), pp. 55-60, 1996.

[6] Osmani M.; Glass J.; and Price A. Architects and contractors attitudes towards waste minimisation. Proceedings of the Institution of Civil Engineers -Waste and Resource Management, 59(2), pp. 65-72, May 2006.

[7] Greenwood, R., Construction Waste Minimisation: Good Practice Guide. CRiBE (Centre for Research in the Build Environment): Cardiff, 2003.

[8] Coventry, S., Shorter, B., Kingsley, M. Demonstrating Waste Minimisation Benefits in Construction. Construction Industry Research and Information Association (CIRIA): London, CIRIA C536, 2001.

[9] Environment Agency. Waste Minimisation Good Practice Guide - Revised. The Environment Agency: Lincoln, United Kingdom, 2001.

[10] Dainty, A.R.J., Brooke, R.J. Towards Improved Construction Waste Minimisation: Improved Supply Chain Integration. Structural Survey 22(1), pp. 20-29, 2004.

[11] Hylands, K. Designing Waste Out of the Construction Process, Proceedings of Minimising Construction Waste Conference: Developing Resource Efficiency and Waste Minimisation in Design and Construction, October 21 2004, New Civil Engineer, London.

[12] Gibb, A. Standardisation and Customisation in Construction: A Review of Recent and Current Industry and Research Initiatives on Standardisation and Customisation in Construction. CRISP: London, 2001.

[13] Baldwin, A., Poon, C., Shen, L., Austin, A., Wong, I., 2006. Designing out Waste in High-rise Residential Buildings: Analysis of Precasting and Prefabrication Methods and Traditional Construction. Proceedings of the International Conference on Asia-European Sustainable Urban Development, eds Y., Baizhan, L. and Stammers, K. Chongqing, China, 56 April 2006, Centre for Sino-European Sustainable Building Design and Construction, Beijing.

[14] AJ PLUS (The Architects' Journal) online,www.ajplus.co.uk/aj100_06/ top100_06/. 